\title{
Development of a set of working units from polymeric materials for the design of combine harvesters
}

\author{
Andrey Izmailov ${ }^{1}$, Maksim Moskovskiy ${ }^{1, *}$, and Dmitriy Podlesniy ${ }^{2}$ \\ ${ }^{1}$ Federal Scientific Agroengineering Center VIM, 1-st Institutsky proezd, 5, Moscow, 109428, Russia. \\ ${ }^{2}$ Don State Technical University, Gagarin Square, 1, Rostov-on-Don, 344000, Russia.
}

\begin{abstract}
In this paper we presents the results of research on the use of new types of products from polymeric materials in the designs of combine harvesters. The use of these modernized polymer structures will reduce the damage of grain by more than $20 \%$, increase the reliability of ongoing technological processes, increase the operational life of the combine.
\end{abstract}

\section{Introduction}

New kinds of polymers are wide application in various branches of mechanical engineering. At the moment, the specific share of polymer products in the construction of grain harvesters is up to average $20 \%$ of the total mass of the machine. The trend towards an increase in this share is due to their design advantages: greater resistance to abrasive actions, reduced friction, low specific gravity, the possibility of a wide variation in the output properties of the material due to the use of various expanded clay additives. Constraining factors of growth are technology of manufacturing parts and assemblies, the cost of raw materials, the lack of research and practical application of assembly units as the main working bodies made of polymer materials $[1,2,3]$.

It is supposed to use the above-mentioned properties of polymers (smaller coefficient of friction and modulus of elasticity, with strength properties), in the construction of grain harvesters as coatings for bunkers, solid guides, combined transporting working elements of harvesting machines, which will improve the conditions of work processes and reduce the damage of grain.

\footnotetext{
* Corresponding author: maxmoskovsky74@yandex.ru
} 


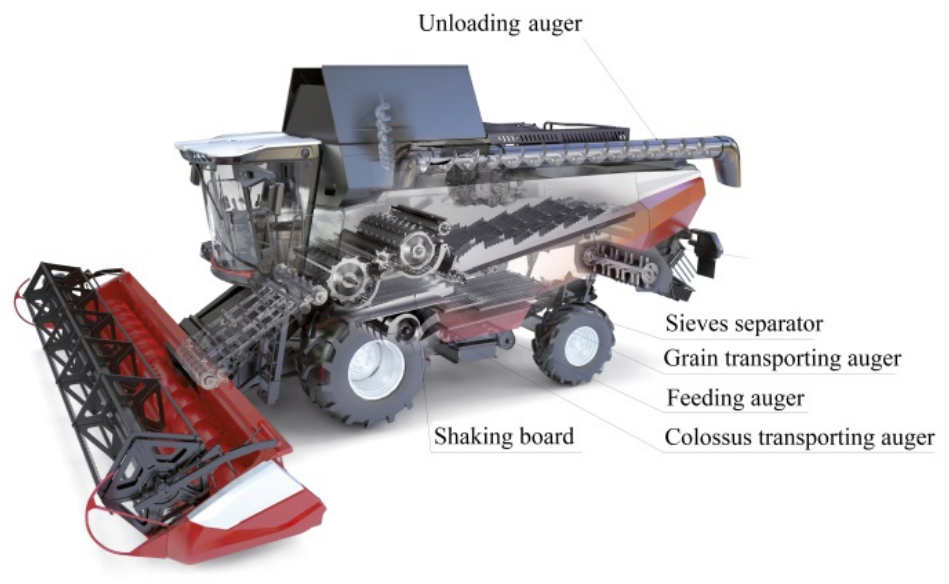

Fig. 1. Complex of working bodies of polymeric materials in the structure harvester combine.

Preliminary economic evaluation of the use of combined working bodies made of polymers fully shows the reduction of production costs due to an increase in the service life and maintenance factor of these products in comparison with standard products made of metal.

All the above assumptions correspond to the general trend in the development of combine-building - increasing the productivity of the machine, reducing losses and damage to grain, ensuring the stability of the technological process of the combine. $[3,4,6]$

The purpose of the research is to justify a new polymer sieve in the construction of a combine harvester under various operating conditions.

\section{Materials and methods}

A particular feature of this sieve is the performance of a working active - separating surface made of ultra-high molecular polyethylene (UHMWPE). That will increase the resource of this sieve and reduce the mechanical effect on the grain material being fed. (Figure 2).

The upper combs are made in the form of plates from the UHMWPE material, in the front part of the modernized combined grate, are installed at an angle to the sieve plane. The grain, which fell directly on the sieve, striking the comb from the polymers, actively passes under the sieve. The upper part of the combs of the front part of the sieve makes it difficult to orient and pass through the slots between the slats of the long components (crushed straw, spikelets, etc.), and also reduce the blocking of the cracks by large heap components.

The upper combs are installed at an angle to the sieve plane. They are made in the form of plates from the UHMWPE material and installed in the front part of the modernized combined sieve. The grain actively passes under the sieve, which fell directly on the sieve, striking the comb from the polymers. The upper part of the combs of the front part of the sieve makes it difficult to orient and pass through the slots between the slats of the long components (crushed straw, colossus, etc.), and also reduce the blocking of the cracks by large heap components. 


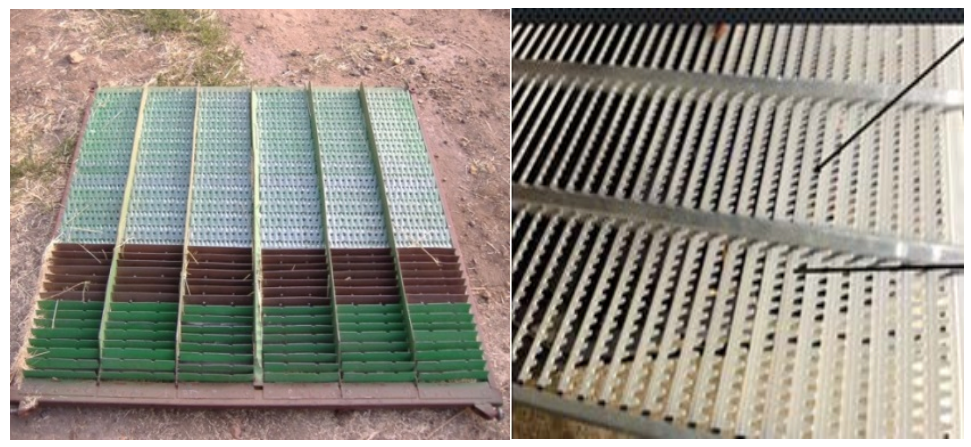

Fig. 2. Experimental combined sieve made of polymer materials.

Due to a similar sieve construction, the probability of multiple rebound reflections of grains in the direction of the heap movement along the front part of the sieve is reduced. Grain passes under the sieve by hitting against the upper combs of the front part of the sieve, which are installed at a large angle to the surface of the sieve. It is also necessary to take into account that the collision of a comb from the UHMWPE material less traumatizes the grain material, due to the coefficient of grain recovery.

The types of gratings and their blinds, the sieve parameters in the grinding mill are determined (Fig. 3, 4).

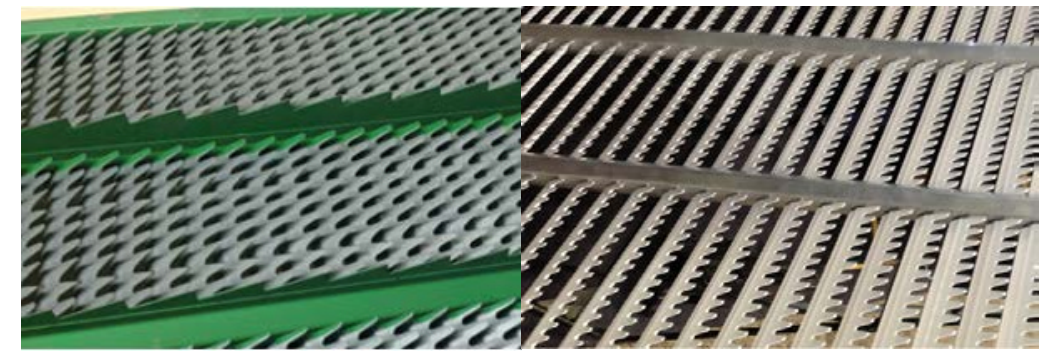

a)

b)

Fig. 3. Sieve for cleaning the combine harvester. a) a metal sieve b) a sieve made of a polymeric material of UHMWPE.

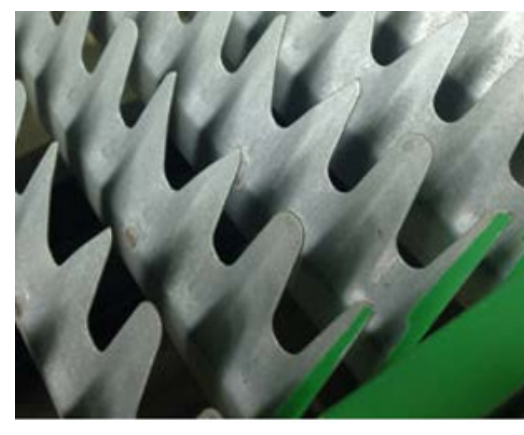

a)

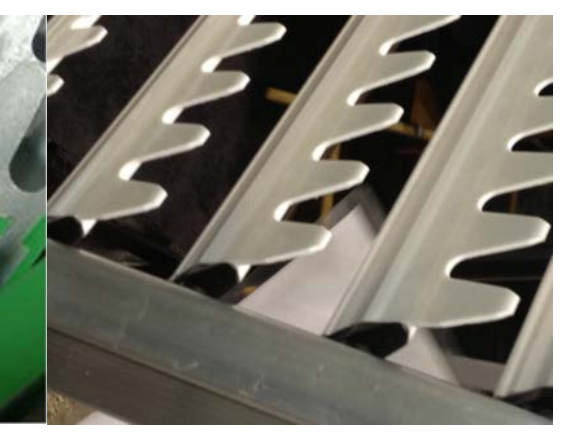

b)

Fig. 4. Type of louvre sieves cleaning the combine harvester a) - metallic, b) - polymer material UHMWPE.

The main parameters of the sieve functioning are determined. (Figure 5). 


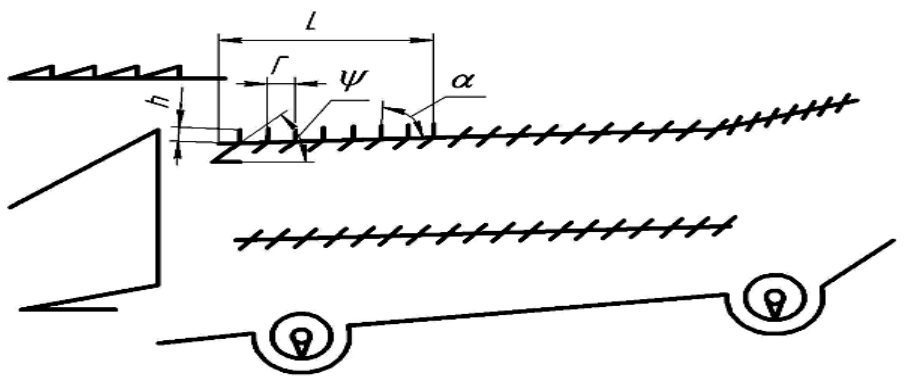

Fig. 5. The main dimensions of the upper sieve with the active-separating surface of the initial section L.

To obtain the results of the experiment with a confidence probability of 0.9 , having been given an allowable error of the measured value $\pm 3 \%$, the required number of replicates of the experiment equal to 3. [5]

The tuning parameters of the airborne sieve cleaner when wheat grain is separated into the upper sieve (Table 1): the opening angle of the upper crests of the forward part of the sieve was $80^{\circ}$, the speed of the air flow is within $4-6 \mathrm{~m} / \mathrm{s}$; the opening of the combs of the back part of the upper sieve $0.014 \mathrm{~m}$; opening of the fins of the upper sieve extension $0.016 \mathrm{~m}$; opening of the bottom sieves $0,01 \mathrm{~m}$.

The angle of the lower part of the combs of the rear part of the sieve is set as in the prototype: the angle of inclination is $\psi=80-90^{\circ}$ with respect to the surface of the louver sieve and the angle of inclination of the upper part of the combs of the rear part of the sieve at the standard angle of the folding of the comb is of the order of $145-155^{\circ}$ to the plane of the louver sieve is $\alpha=115-135^{\circ}$. Dimensions: $\mathrm{h}$ - height of the comb, $\mathrm{r}$ - distance between the combs, taken from the standard matt sieve.

The area of the cleaning sieves is determined by taking the grain-to-straw ratio for the fedding grain heap fraction of $1: 1.5$ and feeding it to the harvester $\mathrm{q}=6-16 \mathrm{~kg} / \mathrm{s}$ (Table $1)$.

Table 1. Area of modernized cleaning sieves

\begin{tabular}{|c|c|c|c|c|c|c|}
\hline $\begin{array}{c}\text { Loading of harvester, } \\
\mathrm{kg} / \mathrm{sec}\end{array}$ & 6 & 8 & 10 & 12 & 14 & 16 \\
\hline $\begin{array}{c}\text { Required area of louvre } \\
\text { sieves, } \mathrm{m}^{2}\end{array}$ & 1.92 & 2.56 & 3.20 & 3.84 & 4.48 & 5.12 \\
\hline
\end{tabular}

Table 2. Variable factors of the investigated object.

\begin{tabular}{|c|c|c|c|c|c|}
\hline Factors & Designation & $\mathrm{X}_{\max }$ & $\mathrm{X}_{\min }$ & $\mathrm{X}_{0}$ & $\begin{array}{c}\text { Code } \\
\text { designation }\end{array}$ \\
\hline Modes of harvester & $\mathrm{X}_{1}$ & 8.25 & 3.5 & 6.1 & $\mathrm{X}_{1}$ \\
\hline $\begin{array}{c}\text { Length of active area of } \\
\text { upper sieve separation, mm }\end{array}$ & $\mathrm{X}_{2}$ & 500 & 400 & 300 & $\mathrm{X}_{2}$ \\
\hline $\begin{array}{c}\text { Incline angle of polymer } \\
\text { louvers }\end{array}$ & $\mathrm{X}_{3}$ & 90 & 85 & 80 & $\mathrm{X}_{3}$ \\
\hline
\end{tabular}




\section{Results and discussions}

The parameters of the separation process on a sieve made of a polymer material of UHMWPE are determined. (Table 3, Figure 6,7)

The combined sieve of the polymer material in the combine cleaning system showed the following values for the main quality indicators: losses were $0.47 \%$, which corresponds to the established agro-industrial requirements, and decreased compared to the standard metal sieve by $7 \%$.

The purity of the grain in the bunker after the polymer sieve has increased by $1.2 \%$ compared to the metal air sieve grating.

We have determined the rational high-speed operation modes for air-cleaning with different types of gratings providing a more "gentle" treatment of the grain material: 1 low-speed operation, feeding $(\mathrm{Q}=3.5 \mathrm{~kg} / \mathrm{sec} \cdot \mathrm{m}) ; 2$ - medium flow mode, feed rate $(\mathrm{Q}=$ $6.1 \mathrm{~kg} / \mathrm{sec} \cdot \mathrm{m}) ; 3$ - high-speed mode, feed $(\mathrm{Q}=8.25 \mathrm{~kg} / \mathrm{sec} \cdot \mathrm{m})$.

Table 3. Distances of falling wheat grains on the upper sieve of air sieve cleaning system for the angle of inclination of the combs $80^{\circ}$.

\begin{tabular}{|c|c|c|c|c|c|c|}
\hline \multirow[t]{2}{*}{$\begin{array}{l}\text { Speed of air } \\
\text { flow, } \mathrm{m} / \mathrm{sec}\end{array}$} & \multirow{2}{*}{$\begin{array}{l}\text { Minimal and } \\
\text { maximal } \\
\text { distance of grain } \\
\text { falling }\end{array}$} & \multicolumn{3}{|c|}{$\begin{array}{l}\text { Lengths of grain collision } \\
\text { area with sieve according to } \\
\text { replicates of experiments, } m\end{array}$} & \multirow{2}{*}{$\begin{array}{c}\text { Average } \\
\text { value of } \\
\text { the } \\
\text { collision } \\
\text { area, } m\end{array}$} & \multirow{2}{*}{$\begin{array}{l}\text { Empirical } \\
\text { dispersion, } \\
\mathrm{S}^{2}\end{array}$} \\
\hline & & №1 & №2 & №3 & & \\
\hline \multirow{2}{*}{4} & Min & 0,058 & 0,063 & 0,062 & \multirow{2}{*}{0,08} & \multirow{2}{*}{0,0003} \\
\hline & Max & 0,093 & 0,096 & 0,1 & & \\
\hline \multirow{2}{*}{5} & Min & 0,078 & 0,08 & 0,079 & \multirow{2}{*}{0,12} & \multirow{2}{*}{0,001} \\
\hline & Max & 0,13 & 0,137 & 0,14 & & \\
\hline \multirow{2}{*}{6} & Min & 0,12 & 0,09 & 0,1 & \multirow{2}{*}{0,165} & \multirow{2}{*}{0,0052} \\
\hline & Max & 0,2 & 0,24 & 0,23 & & \\
\hline
\end{tabular}

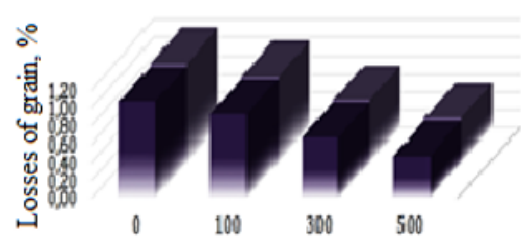

Length of active separation primary area, $\mathrm{mm}$

metal 'plastic

a)

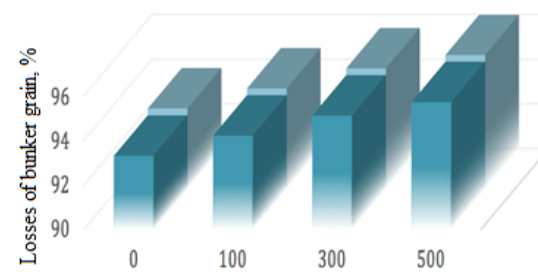

Length of active separation primary area, $\mathrm{mm}$

"metal "plastic

b)

Fig. 6. Comparative analysis of the grain loss (a) and purity characteristics of bunker grains (b) in various sections of sieves made of metal and sieves made of polymer material. 

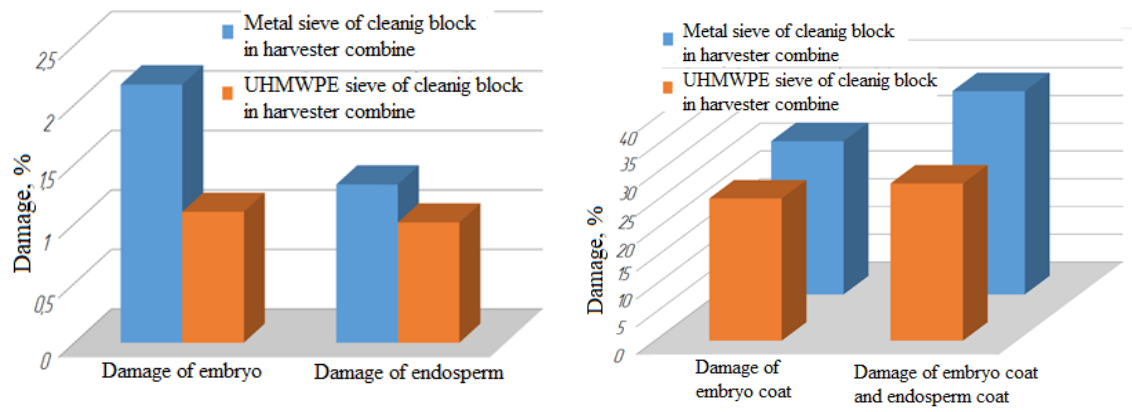

Fig. 7. Comparative analysis of the main macro and microdamages of grain after passing under a standard sieve and sieve made of a polymer material.

\section{Conclusions}

Study have shown that in terms of quality of grain loss and the purity of bunker grains, there is no significant difference when using a standard sieve and a combined sieve from UHMWPE. Subsequent laboratory study on wear resistance have revealed the development of a lattice of polymers by $72.4 \%$ higher compared to metal gratings within the same agriculture term.

Comparative analysis of macro and microdamages of grain showed (with a confidence probability of 0.95 ), a decrease in damage to the embryo after passing under the lattice from polymers by $12 \%$, damage to the endosperm by $10 \%$. This suggests a stable effect of reducing grain damage when using polymeric sieves in grain harvesting machines.

\section{References}

1. Pekhalsky I.A., Moskovskiy M.N., Reduction of seed injury by sieves, Rural mechanizer, 9, pp. 22-23. (2015)

2. Moskovskiy M.N., Pakhomov V.I., Vesnin V.N., Investigation of the interaction of the components of the harvested grain material on the surface of the working organs of the combine harvester equipped with UHMWPE coating, Izvestiya Samara Scientific Center of the Russian Academy of Sciences, 4 (2), pp. $531-533$ (2013)

3. Moskovskiy M.N., Synthesis of system solutions for the technological process of obtaining seeds on the basis of structural-functional modeling, Diss. doc. tech. sciences: , Krasnodar, 491 p. (2017)

4. Moskovsky, M.N., Chumak, I.V., Chaava, M.M., Development of a structuralfunctional model of a single production process obtaining seed material in farms, ARPN Journal of Engineering and Applied Sciences, 13(6), pp. 6414-6418. (2018)

5. Adler Yu. P., Planning an experiment in the search for optimal conditions, Science, 280 p. (1976)

6. Paulsen M. R., Nave W. R., Corn damage from conventional and rotary combines, Transactions of the ASABE.23 (5):

1100 1116. @1980:URL:elibrary.asabe.org/abstract.asp?search=1\&JID=3\&AID=34729\&CID= $\mathrm{t} 1980 \mathrm{vv}=23 \& \mathrm{i}=5 \& \mathrm{~T}=1 \& u r l R e d i r e c t=[$ anywhere $=$ on $\&$ keyword $=\&$ abstract $=\&$ title $=\&$ author $=\&$ references $=\&$ docnumber $=\&$ journals $=$ All $\&$ searchstring $=\& p g=\&$ allwords $=$ grain $\% 20$ near $\% 20 \mathrm{cle}$ an\&exactphrase $=\&$ OneWord $=\& A$ ction $=\mathrm{Go} \& \mathrm{Post}=\mathrm{Y} \& \mathrm{qu}=] \&$ redirType $=$ newresults.asp . 